\title{
Research Universities Stakeholder Report
}

\author{
Ali Andalibi, Nancy Davenport, Barbara DeFelice, Michelle Gluck, Patrick Herron, Mark Newton, \\ Joyce Ogburn
}

Although many of the participants in our working group occupy positions in their home institutions' libraries, they were joined by active researcher colleagues as well as a colleague in a general counsel's office. It may not surprise anyone to hear that while we found common cause in the exploration of the ways in which research universities may advance an open scholarship agenda, we also encountered a refreshing, spirited debate challenging tooeasily accepted fundamental positions on the value of and approach to the development of the open exchange of new knowledge and the pursuit of higher goals attendant to the role of the academy in modern society.

It is not, we discovered, always quite so simple as to recommend that institutions of higher education impress unilateral policies of intellectual property licensure for their open access repositories without rationalizing the tradition of scholarmanaged copyright. And while we may agree to observe openness as a virtue, it is also a vulnerability - the datasets produced by the scholars of our institutions may not be copyrightable, but they encode and express a near-irreproducible intellectual intent, and they represent a life's work. Thus one-size, absolutist approaches to openness fail to capture the needs of our scholars working as best they can within a system of anachronisms (even if it is evolving, slowly) - and these are the creators without whom there would be very little intellectual product about which to debate.

The work ahead will be very challenging-we'll need to think critically and creatively about the development of programs and platforms that explore open scholarship in ways that meet the needs of our scholars. Can we imagine and realize, for example, university-supported platforms for open data sharing that invite peers in as collaborators rather than competitors? Can we incorporate commercialization into our vision of open scholarship as one of several modes of dissemination - or will these forces forever be opposed to a pure vision of openness? The answer to these questions and more suggest a need to revisit the role of the research university as an environment for the support and fostering of new knowledge.

Despite the increasingly risk-averse mechanisms impeding forward process in an era of resource scarcity at the state and federal funding levels, the research university has an obligation to benefit society and the public good at its core, regardless of how invisible or rarely expressed this appears in modern discourse. Real advancement requires support for the innovation and experimentation of our scholars, structures tolerant of failure that admit a new range of techniques and approaches. Anything short of this presents of the authors listed here (in alphabetical order by last name) as well as contributions from other OSI2017 delegates. The findings and recommendations expressed herein do not necessarily reflect the opinions of the individual authors listed here, nor their agencies, trustees, officers, or staff. 
a threat to breakthrough science and research, and breakthrough scholarship, and this concerns us all.

Yet systems developed to provide these supports emerged in a different era of scholarly communication as well. One might well ask, would it even be possible to instantiate the modern research library today, imagining it didn't already exist? As we found this a properly-sobering thought-exercise, we also find within the question the wherewithal to resolve our recommendation for strategic investments in our research libraries and across our institutions, to innovate and experiment in modes of support and partnership with our scholars to elevate their efforts and provide on-ramps to open scholarship that speak to the collective interest. The challenges of supporting open scholarship in the research university are many and involve numerous stakeholders. Research data infrastructure, digital scholarship support, information discovery and access-and the sustainability problems among them-are all challenges that both necessitate and contribute to an increasingly open environment of knowledge generation and exchange. Solutions will come from the numerous stakeholders that comprise our institutions-from our scholars, our libraries, our modes of research computing support, our offices of sponsored projects, and our information technology and high performance computing infrastructure.

What is necessary is dialogue, as well as a party to convene stakeholders, conduct debates, and use these outcomes to expand into creative partnership at local and consortia levels. For each of our stakeholder groups, the mistake we risk is in presuming the necessity of radical transformation in the absence of deliberate dialogue. OSI provides us with one such venue to challenge preconceptions; university libraries with their programs of digital scholarship, scholarly communication support, and outreach, suggest a counterpart at the institutional level.

\section{Research Universities Stakeholder Group}

Ali Andalibi, Associate Dean of Research, Science, George Mason University

Nancy Davenport, University Librarian, American University

Barbara DeFelice, Program Director, Scholarly Communication, Copyright, and Publishing, Dartmouth

Michelle Gluck, Associate General Counsel, George Washington University

Patrick Herron, Senior Research Scientist for Information Science + Studies, Duke University

Mark Newton, Director of Digital Scholarship, Columbia University Libraries

Joyce Ogburn, Digital Strategies and Partnerships Librarian, Appalachian State University 